\title{
CONTRIBUIÇÃO AO ESTUdO DE PARÂMETROS BIOQUÍMICOS SÉRICOS DE UM EXEMPLAR DE ALPACA (Lama pacos).
}

\section{RAFAEL CARTELLI ${ }^{1}$; LIOR PLIACEKOS ${ }^{2}$; ONEIDA LACERDA $^{3}$; METRY BACILA ${ }^{4}$}

${ }^{1}$ Mestrando do Curso de Pós Graduação em Ciências Veterinárias da Universidade Federal do Paraná; Médico Veterinário, Serviço de Medicina de Animais Selvagens e Odontologia Veterinária do Hospital Veterinário da Universidade Federal do Paraná. ${ }^{2}$ Farmacêutico e Bioquímico, Mestrando da Universidade de Ados, Israel. ${ }^{3}$ Médica Veterinária, Zoológico de Curitiba. ${ }^{4}$ Professor Sênior, Curso de Pós-Graduação em Ciências Veterinárias, Universidade Federal do Paraná.

Amostras de sangue de um exemplar de Alpaca (Lama pacos) adulto, do sexo masculino, pertencente ao Zoológico de Curitiba, foram analisadas a fim de determinar os níveis séricos de uréia, desidrogenase lactato (LDH) e glicemia. Após contenção física dos animais, as amostras de sangue foram colhidas em frascos à vácuo sem anticoagulante através da punção da veia safena. Após tal procedimento, as amostras foram centrifugadas a $3.000 \mathrm{rpm}$ por 10 minutos, e o soro sangüíneo das amostras analisado a seguir, através de kits comerciais $\left(\right.$ LABTEST $^{\mathbb{B}}$ ), obtendo-se os seguintes resultados: uréia: 3,6209 $\mathrm{mg} / \mathrm{dl}$; desidrogenase lactato: 313,5188 (onde cada Unidade é igual a 1 micromol de NAD reduzido por minuto por litro de soro nas condições do teste) e glicemia pela técnica da glicose oxidase: 90,5148 mg/dl. Pretende-se realizar análises periódicas para obtenção de valores médios para os parâmetros avaliados.

Palavras Chave: Hematologia, Alpaca, Uréia, LDH, Glucose oxidase 